\title{
Akut pankreatit ile başvuran karaciğer hidatik kistinin endoskopik kist evakuasyonu ile tedavisi
}

Endoscopic cyst evacuation as a treatment for liver hydatic cysts in patients who present with acute pancreatitis

Orhan COŞKUN ${ }^{1}$, Bülent ÖDEMIŞ ${ }^{1}$, Mehmet ALPUA ${ }^{2}$, Erkin ÖZTAŞ ${ }^{1}$, Muhammet Yener AKPINAR ${ }^{1}$

${ }^{1}$ Türkiye Yüksek Ihtisas Eğitim ve Arașttrma Hastanesi, Gastroenteroloji Bölümü, Ankara

${ }^{2}$ Denizli Devlet Hastanesi, Gastroenteroloji Kliniği, Denizli

Hidatik kistin safra yollarına rüptüre olması sık görülen bir komplikasyondur (\%5-25). Intrabiliyer rüptüre bağl oluşan komplikasyonlardan biri de akut pankreatittir. Karaciğer kist hidatiğinin tedavisinde ideal yaklaşım tartıșmalıdır. Tedavide cerrahi yöntemler, perkütan aspirasyon, enjeksiyon ve reaspirasyon metodu ve endoskopik yöntemlerle tedaviler (sfinkterotomi, nazobiliyer drenaj kateteri yerleștirilmesi, stent yerleștirilmesi, kist evakuasyonu) kullanılabilir. Uygun hastalarda safra yollarnna rüptüre olmuş hidatik kistin tedavisinde endoskopik kist evakuasyonu tek başına güvenli ve etkin bir tedavi metodudur.

Anahtar kelimeler: Endoskopik kist evakuasyonu, endoskopik retrograd kolanjiyopankreatografi

\section{GİRIS}

Akut pankreatitin başlıca nedenleri safra taşı ve kronik alkol kullanımı olup tüm vakaların \%75'ini oluşturmaktadır (1). Echinococcus granulosus enfeksiyonunun neden olduğu karaciğer hidatik kistinin intrabiliyer rüptüründen kaynaklanan nadir akut pankreatit vakaları bildirilmiştir (2). Hidatik kistin safra yollarına rüptüre olması sı görülen komplikasyonudur (\% 5-25). Kist hidatiğin safra yollarına açılması nedeniyle oluşan akut pankreatit çok daha nadir olarak izlenen bir komplikasyondur (2). Bu olgumuzda karaciğer kist hidatiği olan ve biliyer açılım nedeniyle akut kolanjit ve akut pankreatit komplikasyonları ile başvuran hastanın endoskopik kist evakuasyonu ile tedavisini sunduk.

\section{OLGU SUNUMU}

Elli yedi yaşında erkek hasta ateş yüksekliği, sarılık, sağ üst kadran ve epigastrik ağrı yakınması ile acile başvurdu. Yapılan kan tetiklerinde lökosit (WBC): 29500/uL, aspartat aminotransferaz (AST): $79 \mathrm{U} / \mathrm{L}$, alanin aminotransferaz (ALT): 56 U/L, gama glutamil transpeptidaz (GGT): $142 \mathrm{U} / \mathrm{L}$, alkalen fosfataz (ALP): $859 \mathrm{U} / \mathrm{L}$, total bilirübin: $11 \mathrm{mg} / \mathrm{dl}$, direkt bilirübin: $6.3 \mathrm{mg} / \mathrm{dl}$, amilaz:1727 U/L, lipaz:2575 U/L bulundu. Bilgisayarlı tomografi (BT) ve ultrasonografisinde (USG) santral yerleşimli $110 \mathrm{~mm}$ boyutlu, düzgün sinırlı, içerisinde
Rupture of hydatic cysts into the biliary system is a common complication with 5\%-25\% frequency. Rupture into the biliary system can cause acute pancreatitis. The ideal treatment modality of liver hydatic cysts is controversial; however, surgery and endoscopic methods such as sphincterotomy, stent insertion, and cyst evacuation are well-known treatment options. In appropriate patients, endoscopic cyst evacuation is a safe and effective endoscopic treatment modality.

Key words: Endoscopic cyst evacuation, endoscopic retrograde cholangiopancreatography

ayrılmış germinatif membranı bulunan tip 2 kist hidatik ile uyumlu görünüm izlendi. Aynı zamanda intrahepatik safra yolları dilate ve koledok çapı $15 \mathrm{~mm}$ olup lümeninde yoğun ekojeniteler izlendi (Resim 1). Hastada karaciğer hidatik kistinin safra yollarına açılmış olduğu ve buna bağlı olarak kolanjit ve pankreatit geliştiği düşünülerek endoskopik retrograd kolanjiyopankreatografi (ERCP) yapildı. ERCP'de papilden kist membranları sarkiyordu (Resim 2). Koledok selektif kanülize edildikten sonra sfinkterotomi yapıldı. Balonla safra yollarından bol miktarda kist materyali temizlendi (Resim 3). Sonrasında kist içerisine basket ilerletilerek kist içerisindeki membranlar basket yardımı ile temizlendi (Resim 4-5). Kist boşluğu serum fizyolojik ile ylkanarak kalan membran partikülleri tekrar balonla temizlendi. Akut kolanjit ve pankreatiti olan hastanın klinik durumu göz önüne alınarak kist içerisine 7 Fr nazobiliyer drenaj kateteri (NBD) yerleştirildi. Kolanjit ve pankreatit kliniği hızla düzelen hastaya tekrar ERCP yapılarak kist boşluğundaki ve safra yollarındaki hidatik membranlar temizlendi. 1 aylık takibinde yakınmalann gerileyen, kan tetkikleri normale dönen ve USG'de intrahepatik ve ekstrahepatik safra yolları normal görünümde olan hasta şifa ile taburcu edildi. 1 ylllık takibinde şikayeti olmayan hastanın son yapılan USG'sinde kist boyutunun 25 mm'ye gerilediği görüldü.
İletişim: Orhan COŞKUN Türkiye Yüksek İhtisas Eğitim ve Araştırma Hastanesi, Gastroenteroloji Kliniği, Kızılay Caddesi, 06100, Sıhhiye, Ankara Tel: +90 31230613 20 • e-mail: drocoskun79@gmail.com Gelis Tarihi: 25.07.2017 Kabul Tarihi: 04.08.2017 


\section{TARTISSMA}

Akut pankreatitin en sık nedenleri safra taşı ve kronik alkol kullanımıdır. Hidatik kistin intrabiliyer rüptüründen kaynaklanan akut pankreatitin nadir vaka bildirimleri vardır. Karaciğer, hidatik kistlerin en sik görüldüğü yer olup (\%50-70) sıklıkla sağ loba yerleşir. Ikinci sıklıkta görüldüğü yer akciğerlerdir (\%20). Nadir olarak dalak, böbrekler, beyin, kaslar, kemik ve pankreasta da kist hidatik yerleşebilir. Hidatik kist, insanlarda yerleştiği organda komşu yapılar üzerinde baskı oluşturana kadar asemptomatiktir. Ancak kistin içindeki hidrostatik basincin artması, kistin rüptüre olmasına neden olabilir (4). Kistin peritoneal veya torasik boşluğa rüptürü anafilaktik şoka veya birçok yeni kist oluşmasına neden olabilir (3). Safra yoluna hidatik kistin rüptürü, karaciğer kist hidatiği olan hastaların \%5-25'inde görülür ve en sık görülen komplikasyondur. Rüptüre olan hidatik kistin içeriği (membranlar, skoleksler, kız kistleri) biliyer kanala atılır. Safra yollarında oluşan obstrüksiyon nedeniyle kolestatik sarllı ve kolanjite neden olabilir. Papiller orifiste membranlar nedeniyle meydana gelen mekanik tıkanıklık sonucu intrapankreatik basıncın artmasına bağlı olarak akut pankreatitin inflamatuvar kaskadı tetiklenir (1). Ayrıca ampulla içerisindeki ekinokok antijenlerine karşı gelişen lokal alerjik reaksiyon da pankreatitin başlamasında rol oynayabilir (1). Bizim olgumuz karın ağrısı, ateş yüksekliği ve sarılık şikayetleri ile başvurmuştu (Charcot tradı). Yapılan laboratuvar ve görüntüleme tetkiklerine ilave olarak ERCP'de papilden sarkan kist membranlarının görülmesiyle kolestaz, kolanjit ve akut pankreatit tanıları konuldu.

Karaciğer kist hidatiğinin tedavisinde ideal yaklaşım tartısmalıdır. Tedavide cerrahi yöntemler, perkütan aspirasyon enjeksiyon ve reaspirasyon (PAIR) metodu ve endoskopik yöntemlerle tedaviler (sfinkterotomi, NBD yerleştirilmesi, stent

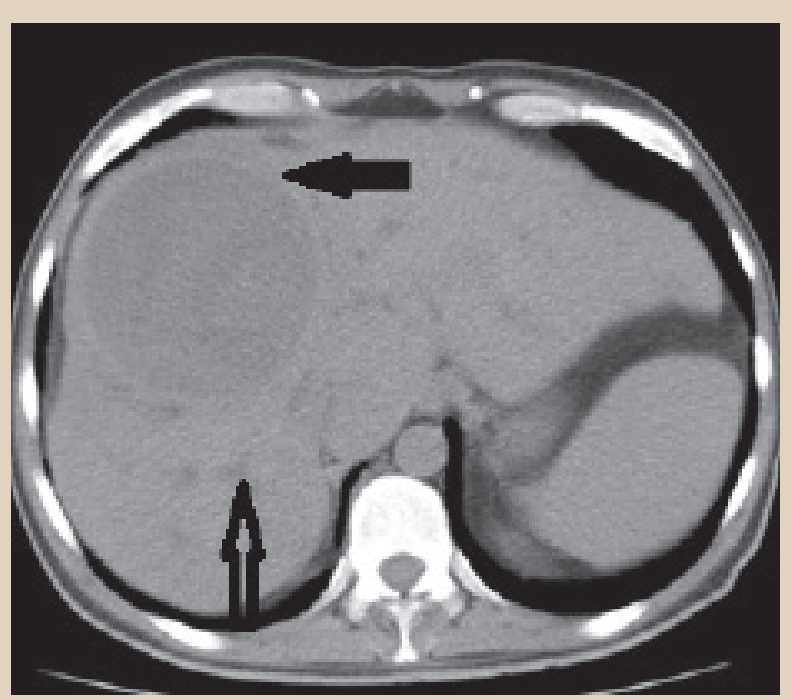

Resim 1. BT'de karaciğer sağ lobda 110 mm çapında düzgün sınırlı hidatik kist (siyah ok), dilate intrahepatik safra yolları (beyaz ok). yerleştirilmesi, kist evakuasyonu) kullanılabilir. Endoskopik sfinkterotomi, safra kanallarnna rüptüre olan hidatik kistlerin tedavisinde etkin, güvenilir ve bilinen bir yöntemdir (7). Albendazol, medikal tedavide cerrahi veya perkütan girişimlerle birlikte kullanılan en etkili antihelmintik ilaçtır. Safra yollarına açılmış hidatik kist vakalarında ERCP ile tedavi edilen birçok vakada, takipler sırasında kist hacminin önemli ölçüde küçüldüğü, \%25'inde hastaların tamamen düzeldiği ve başka cerrahi tedaviye gerek duyulmadığını gösteren çok sayıda çalışma vardır (6). Endoskopik sfinkterotomi (ES), balon veya basket kateteri ile kist içeriğinin ekstraksiyonu yapılabilir. Endoskopik kist evakuasyonu, nazobiliyer dren (NBD) yer-

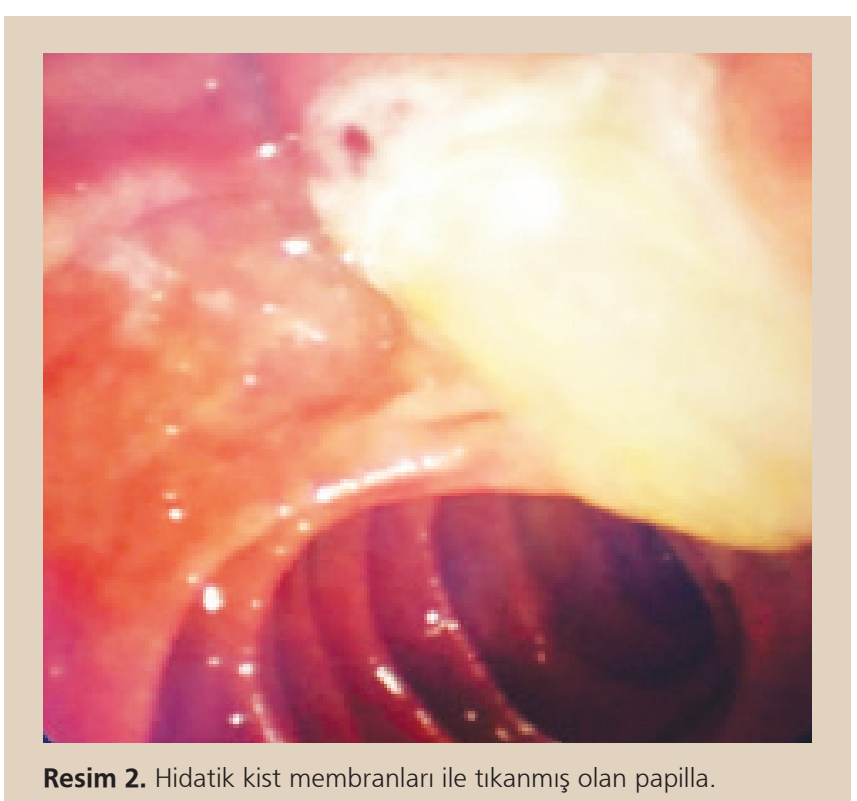

Resim 2. Hidatik kist membranları ile tıkanmış olan papilla.

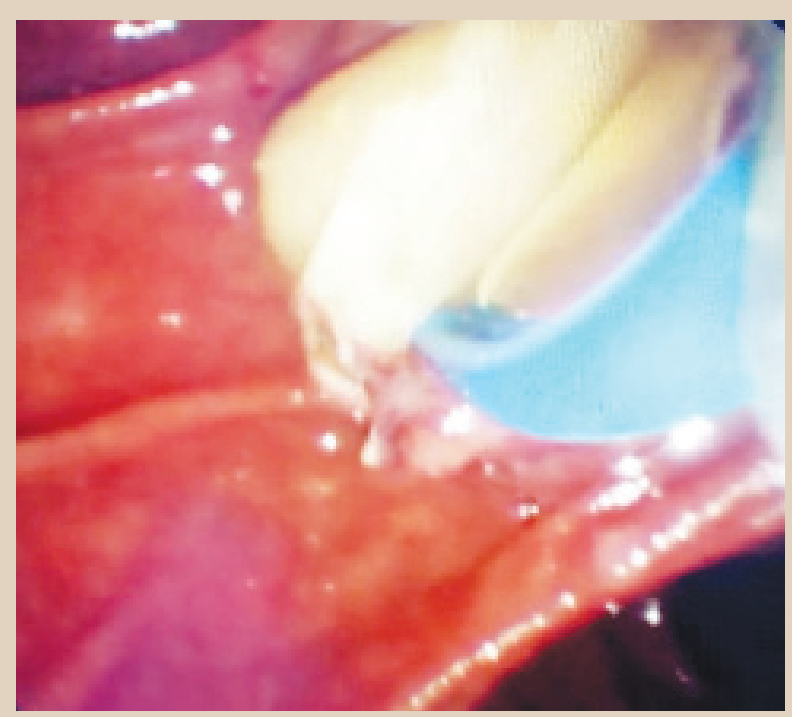

Resim 3. Balonla koledoktan kist hidatik membranlarının temizlenmesi. 
leştirilmesi ve biliyer stent yerleştirilmesi ERCP ile uygulanabilen tedavi yöntemleridir. Akut kolanjit nedeniyle sepsis gelişmiş olan hastalarda, NBD yerleştirilmesi geçici tedavinin ilk tercihi olabilir. Ayrica, kalan hidatik materyali safra yollarından tamamen temizlemek için ERCP tekrar yapılabilir (6). Bizim olgumuz, tek başına endoskopik kist evakuasyonu ile tedavi edildi ve ek bir tedavi yöntemine gerek duyulmadi. Işlem sonrası takibinde kistin boyutu küçüldü.

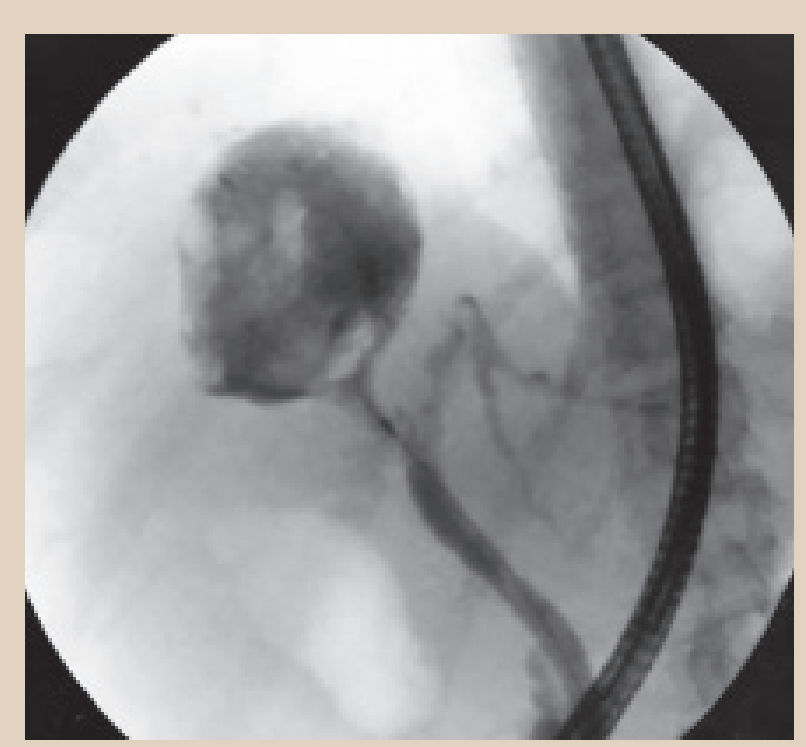

Resim 4. Kist içerisine basket ile girilerek kistin evakuasyonu.
Sonuç olarak hidatik kistin safra yollarına rüptüre olması nedeniyle en sık görülen komplikasyon akut kolanjittir. Ayrıca akut pankreatit nadiren birlikte görülebilir. Kist hidatik için endemik olan bölgelerde, kist hidatiğin biliyer kanala açılması akut pankreatitin olası nedenlerinden biridir. Bu olgumuz, uygun hastalarda safra yollarına rüptüre olmuş hidatik kistin tedavisinde endoskopik kist evakuasyonunun tek başına güvenli ve etkili olduğunu göstermiştir.

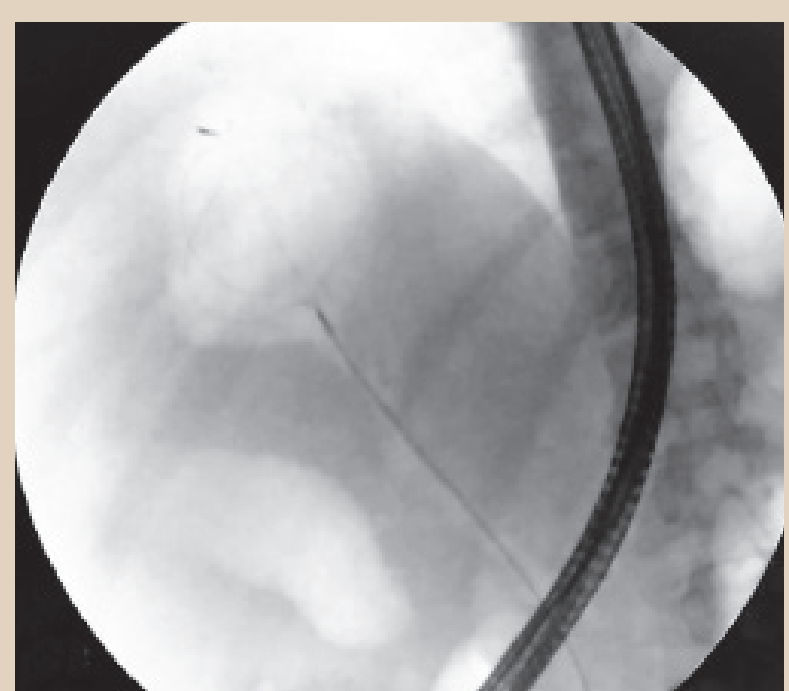

Resim 5. ERCP ile evakuasyon sonrası kist membranları temizlendi ve kist boşluğu hava ile doldu.

\section{KAYNAKLAR}

1. Beltsis A, Chatzimavroudis G, Iliadis A, et al. Intrabiliary rupture of hepatic hydatid cyst presenting as acute pancreatitis and treatment with endoscopic sphincterotomy: report of two cases. Ann Gastroenterol 2005; 18:353-6.

2. Katsinelos P, Chatzimavroudis G, Fasoulas K, et al. Acute pancreatitis caused by impaction of hydatid membranes in the papilla of Vater: a case report. Cases J 2009;2:7374

3. Macris GJ, Galanis NN. Rupture of the echinococcus cyst of the liver into the biliary ducts. Am Surg 1966; 32:36-44.

4. Sherlock S, Dooley J. Diseases of the liver and biliary system.11th Ed. Oxford: Black Well Scientific Publicatins; 2002:511-6.

5. Pavlidis TE, Katsinelos PT, Tsiaousis PZ, et al. Intrabiliary rupture of a large liver echinococcal cyst in an adolescent managed with endoscopic sphincterotomy and albendazole. J Laparoendosc Adv Surg Tech 2006;16:493-6.

6. Dolay K, Akbulut S. Role of endoscopic retrograde cholangio pancreatography in the management of hepatic hydatid disease. World J Gastroenterol 2014;20:15253-61.

7. Bayhan Z, Yilmaz S, Tiryaki Ç, et al. Acute pancreatitis due to rupture of the hydatid cyst into the biliary tract: A case report. NJMR 2014: 22494995 . 